\author{
BULETINUL INSTITUTULUI POLITEHNIC DIN IAŞI \\ Publicat de \\ Universitatea Tehnică „Gheorghe Asachi” din Iaşi \\ Volumul 67 (71), Numărul 1, 2021 \\ Secţia \\ CONSTRUCTII DE MAȘINI \\ DOI:10.2478/bipcm-2021-0001 \\ sciendo
}

\title{
STUDIES ON THE DESIGN MODELS OF HORIZONTAL AXIS WIND TURBINES
}

BY

\section{EUGEN-VLAD NĂSTASE*}

“Gheorghe Asachi” Technical University of Iaşi, Department of Fluid Mechanics

Received: January 11, 2021

Accepted for publication: March 7, 2021

\begin{abstract}
The aim of the paper is to present through a contrastive analysis the main models used in the analysis and design of horizontal axis wind turbines. The basis for designing a rotor for a wind turbine, which is the main element of a turbine that extracts energy from the wind, is the propeller theory. This theory incorporates mathematical models that describe the movement of fluid around the propeller. The paper presents three generically named models, model A, model $\mathrm{B}$ and model $\mathrm{C}$ respectively, used in the analysis and design of the horizontal axis wind turbine's rotor.
\end{abstract}

Keywords: wind turbine; renewable energy; power extracted from wind; coefficient of power; aerodynamics.

\section{Introduction}

One solution to the growing demand for electricity is to use renewable energy sources and more exactly wind energy is mostly preferred over other sources (Ajoko, 2016). In the design of wind turbines, an important task is to design a turbine that extracts as much power as possible from the available kinetic energy of the air flow. Most modern wind turbines are built with a

${ }^{*}$ Corresponding author; $e$-mail: nastase_eugenvlad@yahoo.com

(c) 2021 Eugen-Vlad Năstase.

This is an open access article licensed under the Creative Commons Attribution-NonCommercialNoDerivatives 4.0 International License (CC BY-NC-ND 4.0). 
horizontal-axis similar to the one seen in the Fig. 1. The hub and the blades of the wind turbine are constructed with an aerodynamic design (Patel et al., 2013) and when interacting with the wind the rotor begin to spin. The turbine shaft spins with the blades and is the mechanism that transfers the rotational/mechanical energy of the blades towards the electrical generator.

Generally for increase the rotational speed of the turbine shaft is used a gearbox. The generator converts the mechanical energy from the wind into electrical energy. The turbine tower contains wiring so the generator can send electricity into a transformer or a battery which will eventually distribute usable electric power.

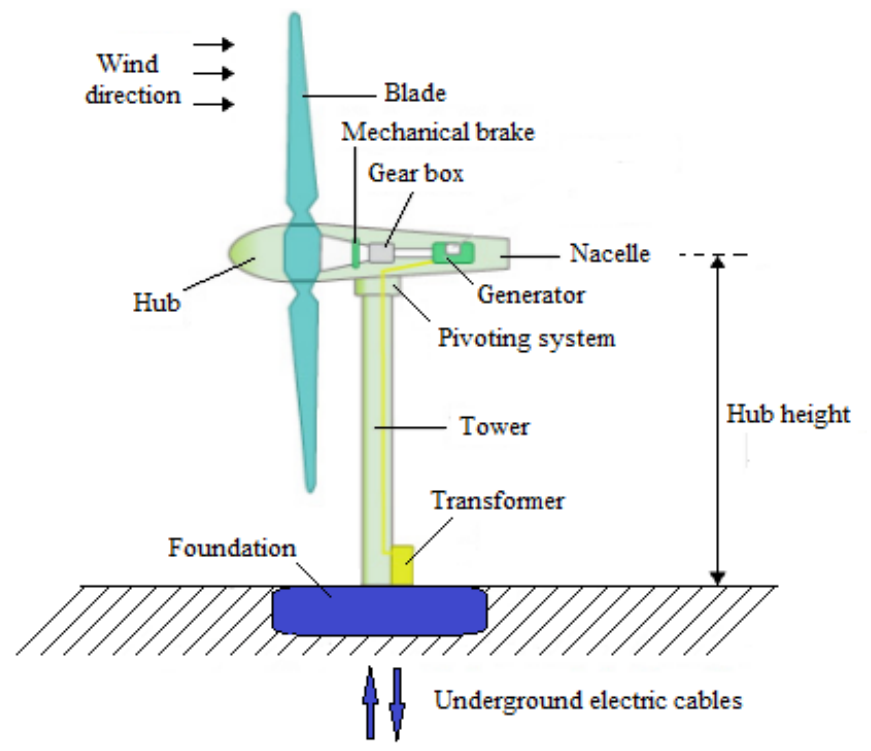

Fig. 1 - Overview of a wind turbine.

A brake is installed to prevent mechanical failure from high wind. The main component that takes the energy of the wind and transforms it into mechanical energy is the rotor (Chandrala et al., 2012). As a result, special attention is paid in the design to the turbine blades (Tenguria et al., 2010).

\section{Problem Description}

At the basis of the design of the rotor of a wind turbine that transforms the kinetic energy of the wind into mechanical energy is the theory of the propeller (Rathore et al., 2011). This theory incorporates mathematical models that describe the movement of fluid around the propeller. The theory of the axial rotor is not unitary, it is presented as a meeting of models and theoretical variants that overlap on certain parts. 
The differences between these models are the result of simplifying hypotheses and approximations as a result of which the general threedimensional motion is replaced by a simpler, approximate motion that uniquely characterizes the essence of the theoretical core. In the case of the axial rotor we can speak of the following models:

1. Models with infinite number of blades, which by neglecting the periodicity lead to an axially symmetrical flow. These models are specific to the free propeller.

2. The ideal propeller model, characterized by symmetrical axial motion without tangential velocities.

3. Fictitious rotor model characterized by symmetrical axial motion with tangential velocities

Neglecting the periodicity of the movement is to replace the real rotor with a finite number of blades with a rotor with an infinite number of blades with an infinitely small thickness. The swept surface will thus be confused with the rotor and when crossing this surface both the speeds and the pressures will show jumps (discontinuities).

The rotor with an infinite number of blades can therefore be assimilated with an active disk. Adopting this point of view the active disk model will naturally incorporate the models of the ideal propeller and the fictitious rotor. The active disk theory consists of two parts: the fundamental part in which the theoretical model is built and the part that connects to the real rotor through appropriate corrections.

The action of the fluid on the active disk is completely determined if the values of the induced velocities in three reference sections located at infinite upstream, rotor plane and infinite downstream are known. As the influence of the active disk is zero at infinity upstream the problem is reduced to the connection between the values of the speeds induced in the plane of the rotor and to infinity downstream within the range of influence (Chandrala et al., 2012).

\section{Design Models}

Model A, based on Rankine and Froude's research, assimilates the propeller with an active disk that can receive a certain amount of motion from the fluid passing through it. The surface of the disk is considered perfectly permeable and normal at each point of it to the current line passing through that point. The model is based on the relationships that derive from the principles of mass and momentum balance and the model of analysis is presented in Fig. 2.

The calculation model results from the analysis of the flow through the domain determined by the rotation of the current line $\mathrm{A}_{\infty} \mathrm{A}_{D} \mathrm{~A}_{3}$, which passes through the $A_{D}$ end of the disk, around the axis of the disk $\mathrm{O}_{\infty} \mathrm{OO}_{3}$. 


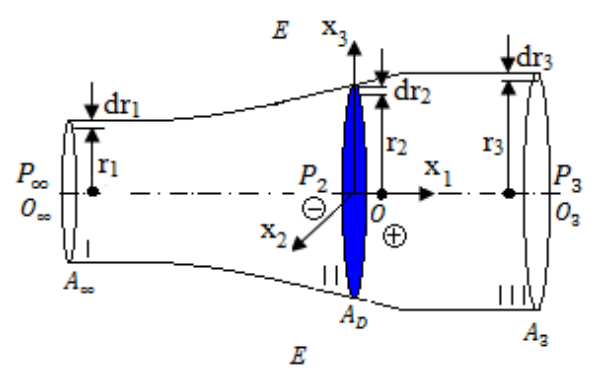

Fig. 2 - Analysis model.

A rotating surface is thus obtained which separates the disturbed flow from the presence of the disk (i.e. zone I-II in front of the disk and zone II-III behind the disk) from the undisturbed movement from the outside (zone E).

The movement around the disc is characterized by an axially symmetrical movement without tangential velocities. The speed field has the following form:

$$
\begin{aligned}
& v_{1}(x)=u_{\infty}-u_{1}(x) \\
& v_{2}(x)=u_{2}(x)=0 \\
& v_{3}(x)=u_{3}(x)=0
\end{aligned}
$$

The disk (propeller) captures energy from the movement of the fluid, so the axial speed through the disk is less than the speed at infinity upstream. The impulse equation, the continuity equation and the Bernoulli equation are applied for the front and back sections of the disk, respectively. Assuming that the infinite downstream pressure is equal to the upstream infinite pressure, the power taken by the disk with the elementary area $d S_{2}=2 \pi r_{2} d r_{2}$ is:

$$
d N\left(r_{2}\right)=\rho\left(u_{\infty}-u_{1}\left(0, r_{2}\right)\right) 2 \pi r_{2} d r_{2}\left(u_{\infty}-\frac{1}{2} u_{1}\left(\infty, r_{3}\right)\right) u_{1}\left(\infty, r_{3}\right)
$$

The power coefficient is obtained as a ratio between the power taken by the disk and the power of the fluid in the area of the disk:

$$
K_{p}\left(r_{2}\right)=2\left(1-\frac{u_{1}\left(0, r_{2}\right)}{u_{\infty}}\right)\left(1-\frac{1}{2} \frac{u_{1}\left(\infty, r_{3}\right)}{u_{\infty}}\right) \frac{u_{1}\left(\infty, r_{3}\right)}{u_{\infty}}
$$

In order to find the maximum value of the power coefficient for a turbine, a connection relationship is required between the axial speed induced in the rotor plane and the axial speed induced at infinity downstream. 
According to the model shown in Fig. 2, the available power in section I is lower than the available power in section II (because $r_{1}$ is smaller than $r_{2}$ ). Relating the power taken by the disk to the available power of the fluid in section I we will find for the power coefficient the expression:

$$
K_{p}^{i}\left(r_{2}\right)=2\left(1-\frac{u_{1}\left(\infty, r_{3}\right)}{2 u_{\infty}}\right) \frac{u_{1}\left(\infty, r_{3}\right)}{u_{\infty}}
$$

This coefficient is maximum if $u_{1}\left(\infty, r_{3}\right)=u_{\infty}$, more precisely in these conditions, the value of the coefficient is unitary. If we impose $K_{p}\left(r_{2}\right)=1$, respecting the condition that the speed induced at infinite downstream is equal to the speed at infinite upstream, we obtain $u_{1}\left(0, r_{2}\right)=0$, which corresponds in the end with the absence of the rotor. This means that the limits (boundaries) of the model have been exceeded. The model provides a good indication for setting the power coefficient but not for blade design because it does not take into account the shape of the propeller (blade).

Because for this model a constant velocity field in sections perpendicular to the propeller axis was considered, a good approximation of reality is made only in the case of a large number of blades, when the speed induced at an arbitrary point of the blade does not differ too much from the average speed.

Model B. If the additional hypothesis of neglecting the deformation of the wake is added to the model described above, keeping the other working hypotheses, the maximum power coefficient that can be used by a kinetic turbine (Betz limit) can be determined. In this situation the working area becomes cylindrical.

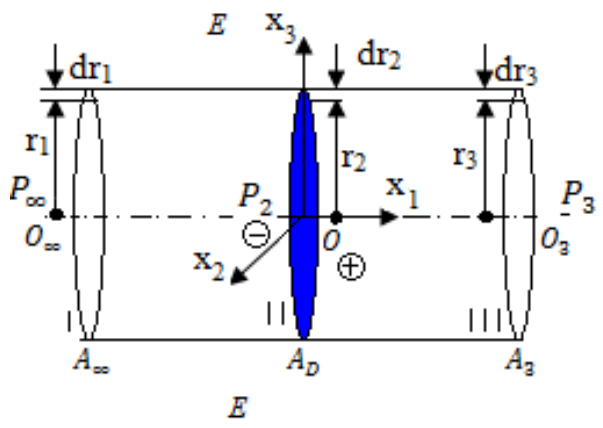

Fig. 3 - Cylindrical model of the field of analysis.

Since the domain is cylindrical, the areas of the elementary sections are equal:

$$
2 \pi r_{1} d r_{1}=2 \pi r_{2} d r_{2}=2 \pi r_{3} d r_{3}
$$


Under these conditions the equation of connection between the speed induced in the plane of the disk and the speed induced at infinite downstream is:

$$
u_{1}\left(0, r_{2}\right)=\frac{u_{1}\left(\infty, r_{3}\right)}{2} \quad r_{1}=r_{2}=r_{3}
$$

Noting, $\quad k\left(r_{2}\right)=\frac{u_{1}\left(0, r_{2}\right)}{u_{\infty}}$ we can rewrite the power coefficient (relation 3) and it will have the expression:

$$
K_{p}\left(r_{2}\right)=4 k\left(r_{2}\right)\left(1-k\left(r_{2}\right)\right)^{2}
$$

Imposing the maximum condition it is determined that it is met for $k\left(r_{2}\right)=1 / 3$ and the maximum value of the coefficient is $K_{p}\left(r_{2}\right)=0.59$.

Model C. The speed of the real movement of the fluid in the propeller track has three components: axial, radial and tangential. Models A and B are based on the impulse method and do not take into account rotational motion. The propeller is replaced by an active disk that causes a sudden increase in fluid pressure without changing the axial velocity component as it passes through it.

The model presented below is based on the integral form of the principles of mass, momentum and kinetic moment. It was initiated by Jukowski and developed by Glauert and also takes into account the rotational movement imprinted on the wake. The presence of this rotational motion is the cause of an additional loss of energy.

The existence of the rotational movement implies the completion of the role of the active disk with its possibility to induce a component tangential to the speed of the fluid passing through it, the other components remaining unchanged by the presence of the disk. The decrease of the static pressure when crossing the disk is determined by the appearance of this tangential component of the speed. Fig. 4 shows the distribution of angular velocities in which: $\omega_{3}-$ angular velocity of fluid at infinite downstream, $\omega_{2}=\omega$ - angular velocity behind the disk and $\omega_{\infty}=0$ from infinite upstream to the front of the disk.

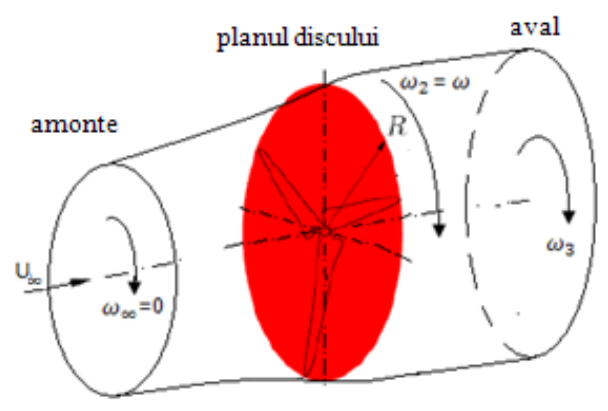

Fig. 4 - Angular velocity distribution. 
To determine the Glauert model, consider an annular elementary current tube that intersects the disk along the circles of radius $r$ and $r+\mathrm{dr}$. Let $V_{x}$ and $V_{r}$ respectively be the axial and radial components of the fluid velocity (Fig. 5). Note with $p_{1}$ and $p_{2}$ the static pressures on the faces of the disk at radius $\mathrm{r}$, with $V_{3 x}$ the axial velocity component $\left(V_{3 r}=0\right)$ and with $\mathrm{p}_{3}$ the wake pressure at infinity downstream at a radius $r_{3}$ of the axis. The disk produces a disturbance of the uniform and axial current from infinity upstream, namely in the area I in front of the disk the fluid velocity has a radial and an axial component.

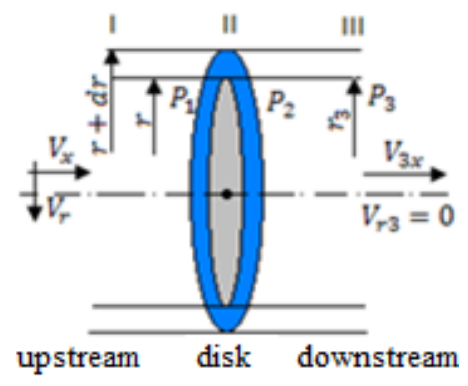

Fig. 5 - The characteristics of the elementary domain.

Applying the continuity equation between sections I and III we have:

$$
V_{x} d S_{p}=V_{3 x} d S_{3} \text { or } V_{x} r d r=V_{3 x} r_{3} d r_{3}
$$

and from the kinetic moment equation, between sections II and III we have that:

$$
\omega r^{2}=\omega_{3} r_{3}^{2}
$$

Applying Bernoulli's equation between sections I-II and II-III respectively we obtain:

$$
\begin{gathered}
h_{\infty}=p_{\infty}+\frac{1}{2} \rho V_{\infty}^{2}=p_{1}+\frac{1}{2} \rho\left(V_{x}^{2}+V_{r}^{2}\right) \\
h_{3}=p_{2}+\frac{1}{2} \rho\left(V_{x}^{2}+V_{r}^{2}+\omega^{2} r^{2}\right)=p_{3}+\frac{1}{2} \rho\left(V_{3 x}^{2}+\omega_{3}^{2} r_{3}^{2}\right)
\end{gathered}
$$

or making the difference between these relationships we have:

$$
h_{\infty}-h_{3}=p_{1}-p_{2}-\frac{1}{2} \rho \omega^{2} r^{2}
$$

This relation shows that the variation of the total pressure at the traversing of the disk is less than the static pressure $\Delta p=p_{1}-p_{2}$ by an amount 
which represents the kinetic energy of the rotational motion imprinted on the propeller.

Relating the motion to the propeller blades rotating at angular velocity $\Omega$, then the relative angular velocity will be $\Omega+\omega$ behind the disk and $\Omega+\omega_{3}$ at infinite downstream. If it is assumed that the relative motion around the blades is potential and preserves the velocity component in the radial plane, then Bernoulli's equation written between the section in front of the disk and the one behind the disk is:

$$
\begin{gathered}
p_{1}+\rho \frac{\Omega^{2} r^{2}}{2}=p_{2}+\frac{\rho}{2}(\Omega+\omega)^{2} r^{2} \\
\Delta p=p_{1}-p_{2}=\rho\left(\Omega+\frac{\omega}{2}\right) \omega r^{2}
\end{gathered}
$$

Also from the previous relations it results:

$$
p_{3}-p_{\infty}=\frac{1}{2} \rho\left(V_{\infty}^{2}-V_{3 x}^{2}\right)-\rho \omega_{3} r_{3}^{2}\left(\Omega+\frac{\omega_{3}}{2}\right)
$$

It is considered a fluid element in the wake, (Fig. 6) with mass $d m$, between the radii $r_{3}$ and $r_{3}+d r_{3}$ and supported by the angle at the center $d \theta$, which rotates with the tangential velocity $\omega_{3} r_{3}$.

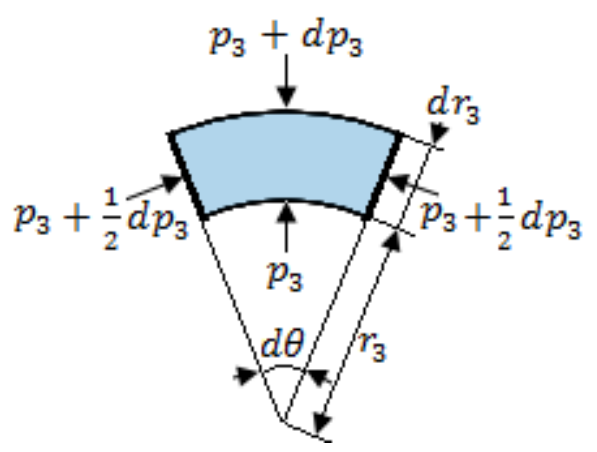

Fig. 6 - The model of an element in the fluid stream.

The fluid element is in radial equilibrium $\left(V_{3 r}=0\right)$ so that the pressure forces balance the centrifugal forces and neglecting small second order infinities we have that:

$$
\frac{d p_{3}}{d r_{3}}=\rho \omega_{3}^{2} r_{3}
$$

Deriving the relation (15) and equaling the result with the one given by (16) we have: 


$$
\begin{gathered}
\frac{d}{d r_{3}}\left[\frac{1}{2} \rho\left(V_{\infty}^{2}-V_{3 x}^{2}\right)\right]-\frac{d}{d r_{3}}\left[\rho \omega_{3} r_{3}^{2}\left(\Omega+\frac{\omega_{3}}{2}\right)\right]=\rho \omega_{3}^{2} r_{3} \\
\frac{1}{2} \frac{d}{d r_{3}}\left(V_{\infty}^{2}-V_{3 x}^{2}\right)=\left(\Omega+\omega_{3}\right) \frac{d}{d r_{3}}\left(\omega_{3} r_{3}^{2}\right)
\end{gathered}
$$

The axial force has the expression:

$$
d T=\rho V_{3 x}\left(V_{\infty}-V_{3 x}\right) d S_{3}+\left(p_{\infty}-p_{3}\right) d S_{3}
$$

Since the axial force appears as a result of the pressure variation on the disk we can write:

$$
d T=\Delta p d S_{p}=\rho\left(\Omega+\frac{\omega}{2}\right) \omega r^{2} d S_{p}
$$

From the equality of these two expressions for the axial force we have:

$$
\frac{1}{2}\left(V_{\infty}-V_{3 x}\right)^{2}=V_{3 x}\left[\frac{\left(\Omega+\frac{\omega_{3}}{2}\right)}{V_{3 x}}-\frac{\left(\Omega+\frac{\omega}{2}\right)}{V_{x}}\right] \omega_{3} r_{3}^{2}
$$

The coefficient of induced axial velocity $(k)$ and induced angular velocity $(h)$ are defined:

$$
\begin{aligned}
& k=\frac{V_{x}-V_{\infty}}{V_{m}} \\
& h=\frac{\Omega+\omega}{\omega}
\end{aligned}
$$

With the help of these equations, the connection between the axial force, the propeller moment and the flow in zone III is determined. The equations deduced above are based on Glauert's theory, which is widely accessible and perhaps the only one suitable for direct applications.

The model being sketched being laborious, certain approximations are made based mainly on the fact that the angular velocity $\omega_{3}$ in the wake is generally low. In the hypothesis $p_{\infty}=p_{3}$, the equation of the elementary axial force and the elementary moment is determined:

$$
\begin{gathered}
d T_{t a}=\rho \pi r d r V_{\infty}^{2}\left(1-k^{2}\right) \\
d M=\rho \pi r^{3} d r V_{\infty}(1+k) \Omega=\rho \pi r^{3} d r \omega V_{\infty}(1+k)(h-1)
\end{gathered}
$$




\section{Conclusions}

Model A provides a calculation relation for determining the power coefficient. When making the model, a constant velocity field in sections perpendicular to the propeller axis was considered, achieving a good approximation of reality only in the case of a large number of blades. Because the model does not take into account the shape of the propeller, it cannot be used when designing the blades of the rotor.

In the model B is added the additional hypothesis of neglect of the wake deformation, keeping the other working hypotheses of the model A. This can determine the maximum power coefficient that can be used by a wind turbine.

For the calculation of a wind turbine it is recommended to use the model $\mathrm{C}$, imposing the condition of minimum energy loss, respectively maximum power coefficient.

\section{REFERENCES}

Ajoko T.J., Horizontal Axial Wind Turbine Blade Design Using Ansys Fluent, Journal of Multidisciplinary Engineering Science Studies, 2, 8, 798-803 (2016).

Chandrala M., Choubey A., Gupta B., Aerodynamic Analysis of Horizontal Axis Wind Turbine Blade, International Journal of Engineering Research and Applications, 2, 6, 1244-1248 (2012).

Patel H., Damania S., Performance Prediction of Horizontal Axis Wind Turbine Blade, International Journal of Innovative Research in Science, Engineering and Technology, 2, 5, 1401-1406 (2013).

Rathore A.S., Ahmed S., Design and Analysis of Horizontal Axis Wind Turbine Rotor, International Journal of Engineering Science and Technology, 3, 11, 79757980 (2011).

Tenguria N., Mittal N.D., Ahmed S., Design and Finite Element Analysis of Horizontal Axis Wind Turbine Blade, International Journal of Applied Engineering Research, 1, 3, 500-507 (2010).

\section{STUDII ASUPRA MODELELOR DE PROIECTARE A TURBINELOR EOLIENE CU AX ORIZONTAL}

(Rezumat)

Scopul lucrării este de a prezenta printr-o analiză contrastivă principalele modele utilizate în analiza şi proiectarea turbinelor eoliene cu ax orizontal. La baza proiectării unui rotor de turbină eoliană, care este principalul element al unei turbine ce extrage energia din vânt, este teoria elicei. În lucrare sunt prezentate trei modele numite generic, modelul A, modelul B şi respectiv modelul C, utilizate în analiza şi proiectarea rotorului de turbină eoliană cu ax orizontal. 